\title{
Max Stirner y la política de la insurrección
}

\author{
Max Stirner and the politics of insurrection
}

VALERIO D'ANGELO*

\begin{abstract}
Resumen: En este artículo se quiere trazar una teoría política de la insurrección en el pensamiento de Max Stirner, en tanto alternativa ética y política a la revolución. Se mostrará que la revolución es en última instancia una estrategia fallida de emancipación en cuanto no libera al individuo de las formas de subjetividad que lo mantienen dependiente del poder. La insurrección, en cambio, puede ser vista como un rechazo de las identidades y de los roles que disciplinan al individuo. Al respecto, se prestará una atención especial al concepto stirneriano de Eigenheit como estrategia ética de auto-determinación y liberación de las formas rígidas de la subjetividad. En última instancia, se querrá mostrar cómo todo el proyecto político de la insurrección stirneriana se basa en un anarquismo ontológico que rechaza la lógica teleocrática del racionalismo moderno y pone en entredicho la misma noción de realización.

Palabras clave: Stirner; Insurrección; Revolución; Liberalismo; Libertad; Eigenheit.
\end{abstract}

\begin{abstract}
The aim of this article to outline a political theory of insurrection in Max Stirner's thought as an ethical and political alternative to revolution. I will show that revolution is ultimately a failed strategy of emancipation as it does not free the individual from the forms of subjectivity that keep her dependent on power. Insurrection, on the other hand, can be seen as a rejection of the identities and roles that discipline the individual. In this regard, special attention will be paid to the Stirnerian concept of Eigenheit as an ethical strategy of self-determination and liberation from rigid forms of subjectivity. Ultimately, I will show how the whole political project of the Stirnerian insurrection is based on an ontological anarchism that rejects the teleocratic logic of modern rationalism and calls into question the very notion of realization.
\end{abstract}

Keywords: Stirner; Insurrection; Revolution; Liberalism; Freedom; Eigenheit.

La rosa es sin porqué, florece porque florece, no tiene preocupación por sí misma, no desea ser vista.

Angelus Silesius

Recibido: 25/07/2018. Aceptado: 08/03/2019.

* Valerio D'Angelo es doctor en filosofía por la Universidad Autónoma de Madrid con una tesis titulada "La noche del mundo. Un análisis de la relación entre nihilismo y política". Su área de especialización es la teoría política moderna y contemporánea, con un enfoque temático sobre nihilismo, teología política, y anarquismo. Entre sus últimos trabajos publicados: "San Max relído. Una defensa de Stirner contra Marx" Revista Internacional de Pensamiento Político (2018) y "De la metafísica a la anarquía. El pensamiento político de Reiner Schürmann”, Logos. Anales del Seminario de Metafísica, vol.49 (2016).

Para contactar con el autor: valeriodangelo@ymail.com 


\section{Introducción}

Si hay una palabra, en teoría política, capaz de dividir a la gente entre apologetas y detractores, es la de Revolución. Toda la historia política y social de Occidente de los últimos dos siglos sería difícil de entender sin acudir a este concepto. De hecho, la Revolución, y las revoluciones, han marcado profundamente el curso de la historia moderna, convirtiéndose en un concepto fundamental a partir de finales del siglo XVIII (Koselleck, 2012, 164). Sin embargo, debido a su intrínseca polisemia y por las distintas teorizaciones acerca de esta noción, se trata de un concepto ambiguo y difícil de definir. La revolución, así como la política misma, está caracterizada por dos tensiones opuestas y contradictorias, esto es, la innovación y la fundación, la "preocupación por la estabilidad" por un lado, y "el elevado espíritu que siempre ha acompañado el nacimiento de algo nuevo sobre la tierra (Arendt, 1992, 230) por el otro. Toda revolución se balancea pues entre un momento destructor de los fundamentos, esto es un "momento de suspensión" (Agamben, 1996) y un momento de re-fundación (Castoriadis, 2000). Entre el anti-fundacionalismo y el fundacionalismo, la anomía y el nomos. El carácter nómico de la revolución será un problema, como veremos en este artículo, para Max Stirner, así como lo fue para muchos teóricos anarquistas a él contemporáneos que, temiendo que la Revolución pudiese pues volver a cristalizarse en instituciones y aparatos burocráticos (la bakuniniana "burocracia roja"), los llevó a proponer una interrumpida revolución desde abajo, una "revolución permanente" (Proudhon, 1947, 36). Más allá de las disputas teóricas, cabe señalar que el concepto de revolución es un relato típicamente moderno, procedente de la convicción ilustrada de que el hombre pudiese dar forma a un nuevo mundo social (Wagner, 2001); por ello, toda acción o ideología emancipadora moderna se ha servido siempre de la gramática de la revolución. Sin embargo, hoy en día, la revolución ha seguido el destino de los grandes metarrelatos políticos que han dominado el siglo XX (Lyotard, 1987). La incredulidad sobre el potencial emancipador de las ideologías políticas tradicionales y, de allí, la ausencia de un centro universal que pueda aunar varias luchas, tal y como ha sido durante casi dos siglos el marxismo, han profundamente transformado el panorama político contemporáneo. A partir grosso modo de los años 70 se ha ido afirmando una pluralidad de luchas identitarias particulares (feministas, LGBT, indígena, etc.), esto es, las conocidas identity politics, basadas en lo que Balibar ha llamado el "estado generalizado de minorías, ante todo en el sentido de que hay, hoy en día, minorías por todos lados" (1995: 53). Sin embargo, cabe preguntarse si estas luchas ponen realmente en entredicho el orden neo-liberal y si no son, en cambio, la expresión misma de la ideología del capitalismo global, que asigna a cada identidad "discriminada" un sitio adentro del sistema (Zizek, 2001, 237).

Entre el Escila del metarrelato revolucionario y el Caribdis de las identity politics, la teoría política moderna ha olvidado otra práctica, más intersticial y "obscura": la insurrección. Asimismo, ha olvidado a su teórico más lúcido: Max Stirner.

\section{La Revolución y sus límites ontológicos-políticos}

Aún largamente ignorado por la teoría política moderna y contemporánea, Max Stirner, nomme de plume de Johan Caspar Schmitt (1806-1856), aporta una contribución significativa para una teoría política de la insurrección. La noción stirneriana de insurrección 
(Empörung), junto con la de Único (Einzige) y propiedad de sí (Eigentum), puede de hecho servirnos de brújula para orientarnos en una realidad política altamente inestable como la nuestra. Esto podría en un principio parecer paradójico en el caso de alguien que, como Stirner, abre su único libro, Der Einzige und Sein Eigentum (1844), con la frase goethiana "he fundado mi causa en nada" (Stirner, 1976, 13), como si quisiera dejar muy en claro la sospecha hacia toda ideología o programa político que pretenda liberar y emancipar al individuo. De hecho, en la filosofía stirneriana no tienen cabida la noción de Causa, ni de Progreso, Humanidad, Razón, y ni siquiera de Sujeto. Todas las categorías que han dominado la modernidad ilustrada no son otra cosa, a los ojos de Stirner, sino esencias, ideas fijas (Idee Fixe) o espectros (Spukt, Genspenst, Sparren), a saber, ilusiones ideológicas que esconden el vacío radical que gobierna la realidad:

La esencia de este mundo, tan atractiva y espléndida, es, para el que busca en sus profundidades, la vanidad, la vanidad es la esencia del mundo (Íbid., 47).

Las categorías universales de Razón, Moral, Verdad, o Sujeto, peligran ante la mirada de Stirner y, sin embargo, su crítica a las esencias y a las identidades fijas no desemboca en un nihilismo impotente sino que, como veremos a lo largo del artículo, se concreta en una ética individual de la autonomía. Es más: solo descubriendo la nada que demora en cada uno y abandonando la idea de un telos que perseguir es posible, para Stirner, poner en entredicho las identidades subjetivas que constituyen nuestra cárcel ideológica. Stirner busca pues una vía de salida del proyecto político de la modernidad, que no ha acarreado aquella emancipación universal que prometía, sino que ha metamorfoseado la vieja dominación en técnicas más refinadas de opresión sobre el individuo. El viejo cristianismo, que la modernidad creía haber desterrado de una vez por todas, no solo no ha muerto sino que ha vuelto bajo la forma del moderno humanismo secularizado: "la religión humana se ha convertido en la última metamorfosis de la religión cristiana" (Ibíd., 176). Asimismo, el liberalismo, detrás de su máscara laica y secularizada, está en realidad plagado de conceptos teológicos, tal y como son, para Stirner, las nociones liberales de igualdad, libertad, y derechos humanos ${ }^{1}$. Estas ideas piden al individuo moderno obediencia y respecto; ellas son, bajo todos los puntos de vistas, "sagradas". Ahora más que antes, quien paga las consecuencias sigue siendo el individuo, que se ve desposeído de su autonomía individual y llamado a cumplir con una serie de deberes y obligaciones. Pero si hay una complicidad, nueva y casi imperceptible, entre modernidad y nuevas formas de dominación ¿cuál es, en este panorama, el papel de la revolución? o sea ¿qué pasa con aquel acto que, más que todos, ha marcado el paso de la modernidad? Ha llegado pues el momento de adentrarnos en la distinción stirneriana entre revolución e insurrección:

Revolución (Revolution) e insurrección (Empörung) no son sinónimos. La primera consiste en una transformación (Umwandlung) del orden establecido, del status del

1 Stirner distingue entre tres liberalismos: liberalismo político (o liberalismo propiamente dicho); liberalismo social (o comunismo) y liberalismo humanitario (o humanismo). Su crítica se concentra en el apartado "Los libres" (Stirner, 1979, 102-148). 
Estado o de la Sociedad; no tiene, pues, más que un alcance político o social. La segunda conduce inevitablemente (unvermeidliche Folge) a la transformación de las instituciones establecidas. Pero no surge con este propósito, sino por el descontento de los hombres. No es un motín, sino el alzamiento de los individuos (eine Erhebung der Einzelnen), una sublevación que prescinde de las instituciones que pueda engendrar. La revolución tiende a organizaciones nuevas, la insurrección conduce a no dejarnos organizar, sino a organizarnos por nosotros mismos, y no cifra sus esperanzas en las organizaciones futuras (Íbid., 322).

Como se desprende de este denso pasaje, la distinción entre revolución e insurrección no se refiere tanto al "éxito" de los dos movimientos (que en ambos casos es el derrocamiento del Estado y del orden existente), sino a sus motivaciones y finalidades. De hecho, contra la imagen de la revolución como clinamen de una transformación epocal (compartida tanto por los revolucionarios como por los contra-revolucionarios), Stirner le atribuye un papel más bien modesto. Su objetivo, nos dice, no es nada excepcional, ya que ella solo procura superar un orden, particular y específico, que será remplazado por otro orden "superior", pero sin nunca poner en entredicho el Orden en cuanto tal. El primer problema que entraña la acción revolucionaria es pues de orden ontológico: la revolución sigue gravitando alrededor de un arché, de un fundamento último que gobierna la realidad social y política. Desde esta perspectiva, la revolución no es aquel movimiento demoledor que los revolucionarios fomentan y que los contrarrevolucionarios temen, sino más bien una reforma, que ha eliminado "los viejos abusos inmorales, para establecer sólidamente usos morales; es decir, no hizo más que poner la virtud en lugar del vicio" (Ívi). La revolución, en pocas palabras, no ha sido capaz de "cortar la cabeza del rey", para usar una expresión foucaultiana, esto es, de deshacerse del principio de la soberanía:

Hasta el día de hoy, el principio revolucionario no ha cambiado: no atacar más que a una u otra institución determinada, en una palabra, reformar. [...] Siempre un nuevo amo es puesto en lugar del antiguo, no se demuele más que para reconstruir, y toda revolución es una restauración (Ibíd., 323).

La teoría y la praxis revolucionaria se caracterizan pues por aquella que podríamos llamar una continuidad en la fractura: a pesar del cambio óntico, como por ejemplo en las instituciones, en la moral y en las costumbres, hay una continuidad ontológica entre el viejo y el nuevo orden. Este concepto queda claro en el análisis stirneriano del derecho revolucionario. De hecho, según el filósofo de Bayreuth, los revolucionarios nunca quisieron liberarse del derecho tout court, sino solo del viejo orden jurídico en pos de uno nuevo y supuestamente mejor. El afán de las fuerzas revolucionarias para dotarse de una nueva constitución demuestra que ellas también compartían "el espíritu burgués de la legalidad", esto es, la confianza casi fideística en el papel del derecho como garantía de estabilidad y de paz social. Igual que los juristas liberales, las cabezas revolucionarias "no se proponen nada más que sujetarnos a un nuevo Derecho tan sagrado como el antiguo" llamándose ahora este derecho "derecho de la sociedad" o "derecho de la Humanidad" (Íbid., 190). Además, respecto de la maquinaria jurídica del ancient regime, imperfecta y limitada, el 
orden pos-revolucionario convierte el derecho en universal, sometiendo todos y cada uno de los ciudadanos al imperio de la ley. Pero, para Stirner, la tan decantada igualdad de derechos no significa otra cosa que la nivelación de las diferencias individuales y su reducción a una identidad política gobernable: el sujeto de derecho, o sea, el ciudadano. Volveremos sobre el asunto dentro de poco, pero de momento es preciso hacer hincapié en la crítica stirneriana al derecho revolucionario como momento fundacional del Orden. Kelsen, en su trabajo sobre el nacimiento de la norma fundamental de un ordenamiento político-social, no llegará a conclusiones muy distintas de las de Stirner. Según el jurista austríaco, la revolución tiene un papel fundamental en la creación del derecho y, ante todo en la creación del mismo orden jurídico como Grundnorm. "La importancia de la norma fundamental -dice Kelsense manifiesta particularmente en los casos en que un orden jurídico sustituye a otro no por la vía legal sino por una revolución. Es, por otra parte, en el momento en que un derecho se encuentra amenazado en su existencia cuando su naturaleza aparece más claramente" (Kelsen, 2009, 114). Así, también para para Kelsen, como para Stirner, la revolución es el momento normativo fundamental de todo nuevo ordenamiento. La continuidad ontológica entre el estamento revolucionario y el orden precedente, como ha quedado evidente en el examen del Derecho, acerca asombrosamente la revolución a la reacción:

La revolución produjo la reacción, y esto muestra lo que era la revolución en realidad [...] los jóvenes violentos, los estudiantes escandalosos y descreídos que desafían todas las conveniencias no son, propiamente hablando, más que filisteos; lo mismo que estos últimos, tienen como único objetivo las conveniencias. Desafiarlas por fanfarronada, como lo hacen, es todavía conformarse con ellas, es, si se quiere, aceptarlas de manera negativa; convertidos en filisteos, se someterán a ellas un día y se conformarán positivamente (Stirner, 1976, 322).

El desafío de los "estudiantes escandalosos” y los “jóvenes violentos” (¿tal vez una referencia al joven Hegel?) se queda vacuo y superficial en tanto no ataca el orden ontológico mismo. Aunque las verdades tradicionales (el milagro, el derecho divino) sean ampliamente cuestionadas por los espíritus ilustrados, "si se ataca a la verdad misma, inmediatamente todos se vuelven creyentes o se nos vienen encima" (Íbid., 53). Hay pues una complicidad implícita entre el orden establecido y la acción revolucionaria o, si queremos, entre el poder constituido y el poder constituyente. Exactamente lo mismo que pasa entre el creyente y el ateo, ya que este último siempre "se toma en serio" la causa del primero. La revolución, en pocas palabras, es incapaz de abandonar el terreno del fundacionalismo. Ella, podríamos decir, hace de eco a la revolución teológica de Feuerbach: así como el humanismo “deja la piel de reptil de la vieja religión para revestir una nueva piel religiosa" (Íbid., 54), del mismo modo la revolución no supera de ninguna manera el viejo orden, sino que lo re-propone bajo un nuevo disfraz. Igual que la revolución teológica reafirma la opresión religiosa sustituyendo Dios con el Hombre, del mismo modo la revolución política sustituye un sistema jurídico por otro, los vicios por las virtudes, etc. pero manteniendo inalterada la dependencia de un orden, un arché. También para Agamben, el problema inherente al proceso de secularización política de conceptos teológicos es que "no hace otra cosa que trasladar la monarquía celeste en monarquía terrenal, pero deja intacto el poder". Por ello, 
según el filósofo italiano, la secularización no es sino "una forma de remoción que deja intactas las fuerzas, limitándose a desplazarlas de un lugar a otro" (Agamben, 2005, 102). De allí que la revolución, en tanto hija y producto de la secularización, está condenada a quedarse atrapada en el orden soberano.

Relacionado con este primer-y contundente-problema, hay otro que lleva Stirner a distanciarse de la revolución como estrategia de emancipación. Según el filósofo de Bayreuth, la revolución y el orden liberal que de ella desciende acuden a la retórica progresista y emancipadora de los derechos y las libertades para engendrar un tipo de gobernabilidad sobre el individuo más imperceptible y por ende más luciferino. No se trata de que el lenguaje de los derechos y las libertades sea mera "retórica vacía", luego desatendida en la práctica, sino de que los valores de libertad, igualdad, derechos, etc., se basan en realidad en una muy específica conceptualización del sujeto liberal (de raigambre ilustrada y humanista) que acaba alienando aún más al individuo (Newman, 2005, 27). Las nuevas libertades logradas a través de la revolución, si por un lado liberan al individuo de algunas viejas formas de opresión, por el otro lo sujetan aún más a un nuevo sistema de dominación:

¡Libertad política! ¿Qué tenemos que entender por eso? Libertad política supone que el Estado, la "polis", es libre, y, la libertad religiosa que la religión es libre, lo mismo que libertad de conciencia supone que la conciencia es libre. Ver en ellas mi libertad, mi independencia frente al Estado, la religión o la conciencia, sería un contrasentido absoluto. No se trata aquí de "mi libertad", sino de la libertad de una fuerza que me gobierna y oprime. Estado, religión o conciencia son mis tiranos, y su libertad implica mi esclavitud (Stirner, 1976, 111).

En este fragmento, claramente inspirado en Zur Judenfrage (1844) de Marx (2006, 36-37), Stirner hace hincapié en el sentido de las nuevas libertades. Así como para Marx la libertad de religión no significaba la liberación de la sociedad civil respecto de la religión, sino la libertad de la religión para mejor invadir la sociedad civil, asimismo para Stirner la libertad política no es la libertad del individuo respecto del yugo del Estado, sino la libertad que gana el Estado respecto de aquellos organismos intermedios (las castas, los gremios etc.) que amparaban el individuo de la mirada directa del soberano. El individuo se convierte así en un "protestante político" que está en relación directa e inmediata (sin mediación) con el Estado. Todas las diferencias individuales quedan borradas bajo la identidad política anónima y universal del ciudadano:

La revolución ha comenzado, como pequeña burguesa, por la elevación del tercer Estado, y va creciendo sin haber salido de su trastienda. Quien es libre no es el hombre en cuanto individuo [...] sino el burgués, el ciudadano, el hombre político que no es un hombre sino un ejemplar de la raza humana, y más especialmente, un ejemplar de la especie burguesa, un ciudadano libre (Stirner, 1976, 115).

Stirner ve en el ciudadano no solo una nueva figura jurídica (el "titular de derechos y deberes") sino precisamente un nuevo tipo de subjetividad gobernable (junto a la del trabajador y del Hombre). El Estado - dice Stirner despejando cualquier duda - es irrespetuoso 
del individuo y solo quiere "hacer de Mí otro Yo, un buen ciudadano" (Íbid., 319). Por ello, cuando Stirner afirma que "el impulso hacía una libertad determinada implica siempre la perspectiva de una nueva dominación" (Íbid., 163), hace hincapié en el carácter ambiguo de toda libertad: ella es condicionada al cumplimento de toda una serie de preceptos, modelos de conducta, normas, etc. Para poder disfrutar de los derechos y libertades, el individuo debe conformarse a un tipo de subjetividad normalizada. Está claro que todos aquellos que, como el vagabundo, la prostituta, el apostador, etc. (pero hoy podríamos decir el sans-papies, el desempleado, el enfermo mental) no consiguen cumplir con esta identidad normalizada, se convierten en parias de la sociedad. Foucault le hará de eco a Stirner cuando, analizando los procesos de subjetivación en el orden (neo)liberal, descubre que este sistema ya no gobierna a través de la represión y la negación de las libertades, sino creando el sujeto en tanto sujeto libre. El homo economicus liberal es un individuo perfectamente libre de perseguir sus intereses, maximizar su beneficio o descubrir su "verdadero yo". El liberalismo es "consumidor" de libertad: "está obligado a producirla y está obligado a organizarla. El nuevo arte gubernamental se presentará entonces como administrador de la libertad" (Foucault, 2007, 84). Para Foucualt, como para Stirner, hay una relación problemática entre libertad y técnicas disciplinarias de gobernabilidad: la libertad abstracta liberal, pero también la libertad del socialismo revolucionario es una hoja de doble filo que, a la vez que procura liberar al individuo, le encadena aún más a específicas formas de subjetivación (Newman, 2011, 194). Ella, paradójicamente, libera sometiendo. Asimismo, también el principio revolucionario de la igualdad de los seres humanos no es otra cosa sino una estrategia de negación ulterior de las diferencias individuales y su reducción a una identidad gobernable. Igualdad quiere decir, según Stirner, igual sometimiento de todos a la autoridad, total conformidad a los deberes y quehaceres que el Estado dicta "si cumple las condiciones requeridas". En conclusión, Stirner se pregunta, nietzscheanamente, qué tipo de régimen o discurso epistémico hace posible la libertad (pero también la igualdad y los derechos), desvelando todo un entramado de poder, saber, poder disciplinario a través del que se construye la identidad social. En el nuevo régimen, afirma Stirner de manera sugerente, "cada prusiano lleva un gendarme en el pecho", indicando con ello una transformación del sujeto (liberal) que se conforma tranquila y voluntariamente, sin necesidad de coacción externa alguna, a toda una serie de preceptos, códigos de conducta, comportamientos socialmente aceptados, premios, compensaciones, etc. Stirner también apoda hombre artificial (Gemachter mensh) al individuo de las sociedades liberales, describiéndolo como una triste figura que ya ni siquiera precisa ser gobernado en tanto "funciona automáticamente". De hecho, una vez que el liberalismo se ha afirmado como ordenamiento razonable (vernünftige Ordung) y el imperio de la Razón ha colonizado todas las relaciones humanas, no es de sorprender que el individuo se convierta en una especie de títere sin titiritero que responde automática y mecánicamente a los dictámenes de la razón instrumental. Pero, según Stirner "si la razón reina, entonces la persona tiene que esclavizarse a ella" (Íbid., 110).

Aunque se le pueda reprochar a Stirner no distinguir adecuadamente la revolución del régimen pos-revolucionario, quedan finalmente claras las razones de su hostilidad a la Revolución. Ella, igual que la restauración, igual que el orden liberal, igual que cualquier orden, vincula los individuos a un principio, a un arché que encadena el sujeto a la dictadura del telos y de la racionalidad instrumental. El individuo sigue estando abocado a la que Reiner 
Schürmann ha llamativamente llamado la dictadura del "origen arqueo-teleocrático", esto es, el sometimiento de nuestra experiencia de seres finitos a un principio absoluto (arché), como el Uno, Dios, el Cogito, la Razón, etc. (Schürmann, 1986, 204). También Camus, de manera no muy diferente de Stirner, notó que las teorías revolucionarias del siglo XIX, y especialmente el nihilismo ruso, sometían el mundo y las cosas a la lógica teleocrática que gobierna todo el modelo "productivo" occidental, que vincula la acción política a un télos, a una constante y frenética realización de un objetivo (Camus, 1978)².

A la luz de lo dicho, no hay ninguna razón para preferir un apocalipsis revolucionaria al orden establecido en tanto ambos estamentos legitiman al Orden y determinados tipos de subjetividades controlables. Para decirlo en las palabras de Pessoa: "el grupo que hace la revolución tiene la misma mentalidad y el mismo carácter del grupo que ha sido derrotado y sustituido por aquella revolución. Por ello, podemos definir la revolución como una "manera violenta de dejarlo todo como era antes"” (Pessoa, 1990, 63). De otra índole es la insurrección.

\section{La Insurrección: el "sentido oceánico de la individualidad"}

La insurrección (Empörung) marca un cambio neto respecto del paradigma revolucionario tradicional:

La revolución tiende a organizaciones nuevas, la insurrección conduce a no dejarnos organizar, sino a organizarnos por nosotros mismos, y no cifra sus esperanzas en las organizaciones futuras. Es una lucha contra lo que está establecido (das Besthende) en el sentido de que, cuando triunfa, lo establecido se derrumba por sí solo (das Besthende von selbst züsammenstürzt). Es mi esfuerzo para desprenderme del presente que me oprime (sie ist nur ein Herausarbeiten Meiner aus dem Bestehenden). Cuando lo he logrado, ese presente muere y, naturalmente, se descompone. En suma, no siendo mi objetivo derribar lo establecido, sino elevarme por encima, mis intenciones y mis actos no tienen nada de político, ni de social; son egoístas porque no tienen otro objetivo que Yo y mi individualidad (Stirner, 1976, 322).

Mientras la revolución es, como se ha visto, la negación de un determinado dominio óntico, la insurrección es en cambio una "negación metafísica”, esto es una negación perpetua y sin mediación del existente. En este sentido, la insurrección es ontológicamente anárquica: ella no quiere cambiar un existente por otro sino desestabilizar los mismos fundamentos ontológicos del existente. Mientras el revolucionario transforma la realidad pero deja sin tocar la dependencia del individuo de un principio (un Orden, una Ley, una

2 Compárense, por ejemplo, estos dos pasos de Camus y de Stirner. Camus: "Dios no ha muerto totalmente para los jacobinos más que para los hombres del romanticismo. Conservan todavía el ser supremo. La Razón, de cierta manera, es todavía mediadora. Desde el momento en que los principios eternos sean puestos en duda al mismo tiempo en que la virtud formal, en que queden desacreditados todos los valores, la razón se podrá en movimiento sin referirse ya no sino a su éxito" (Camus, 1978, 124); y Stirner “¿Quién, pues, "se sacrifica”? El que subordina todo lo demás a un fin, a una decisión, a una pasión, etc. [...] La vocación del sacerdote lo llama a vivir exclusivamente para la idea, a no obrar sino en atención a la idea, a la buena causa (Stirner, 1976, 81). 
Moral, etc.) que le trasciende, el rebelde "ya no se cuida" del existente sino que se alza por encima de ello, lo abandona y, así haciendo, lo vacía quitándole todo fundamento. El insurrecto, en otras palabras, no pone ninguna confianza en la trasformación palingenética de la realidad, si antes el individuo no ha conseguido desprenderse de su apego a las ideas fijas $^{3}$. Para Stirner, un ejemplo histórico de insurrecto (ein Empörer) fue el propio Cristo que "no trataba de derribar a un gobierno (Staatsumwälzer), sino de elevarse él mismo" y "seguir su propia vía” fuera y más allá de la política (Ibíd., 324). Rebelándose, el individuo se desprende de las hipóstasis (políticas, sociales, culturales) objetivadas de su tiempo y descubre a sí mismo como el único creador y propietario del mundo objetivo. Por esto Stirner habla también de la insurrección como de un acto de conversión de lo extraño y ajeno (Fremdheit) en lo propio (Eigen):

Lo que para mí es sagrado, no me es "propio" y si, por ejemplo, la propiedad de otro no me fuera sagrada, la consideraría mía y me la apropiaría en cuanto tuviera la mejor ocasión (Íbid., 45).

La de-sacralización quita a la cosa, o sea al objeto sagrado, su ajenidad y extrañeza convirtiéndolo en propiedad (Eigentum) del individuo. Contrariamente a una interpretación difundida, que asimila el egoísta stirneriano al individuo adquisitivo neo-liberal, defensor de la propiedad privada (una especie de libertarian ante litteram), vemos aquí que la noción stirneriana de propiedad no puede de ninguna manera ser reducida a una dimensión únicamente material, sino que es más bien un ejercicio de poder cuya finalidad es precisamente quitarle a la cosa su aura sagrada e intocable: “¿Qué es, pues, mi propiedad? Lo que está en mi poder y nada más. ¿A qué estoy legítimamente autorizado? A todo aquello que puedo" (Íbid., 261). A pesar de que Marx le reprochara a Stirner cierta "confusión" entre propiedad material y objetiva (la propiedad privada que los comunistas quieren abolir) y propiedad inmaterial (las ideas), Stirner entiende que toda propiedad, material o inmaterial, responde a la misma lógica: algo es mío solo en la medida en que soy capaz de ejercer un poder sobre ello. Propietario no es, en Stirner, una característica o una calidad del individuo, de una sustancia, de un ser, "propietario deber ser entendido aquí como "tener poder" (Sini, 1984, 198).

Pero entender de este modo la propiedad tiene dos claras consecuencias, ontológicas y políticas. Ontológicamente, la apropiación pone en entredicho todo fundamento, esencia o identidad fija, para devolver "la cosa" sagrada al libre uso. Esta estrategia se asemeja a lo que Agamben llama "profanación", esto es, al acto de quitarle la sustancia sagrada del objeto profanado y restituirlo al libre uso por parte del individuo: "pura, profana, libre de los nombres sagrados es la cosa restituida al uso común de los hombres. Pero el uso no aparece aquí como algo natural: a él se accede solamente a través de una profanación" (Agamben, 2005, 28). Políticamente, lleva a cuestionar no solo la misma noción de propie-

3 David Leopold ubica Stirner en la corriente del anarquismo débil, donde con este término indica un comportamiento individual que no tiene porqué oponerse al Estado y sus leyes, y hasta puede en algunos casos obedecerle si así lo piensa conveniente. Distintamente del anarquista "fuerte", que asume a-priorísticamente que todas las leyes y todos los Estados son ilegítimos y entonces prescribe la desobediencia absoluta, el anarquista "débil" no se siente preso de ningún obligo, ni de obedecer ni de desobedecer a las leyes, sino que es libre de decidir según su propia utilidad en base a la circunstancia (Leopold, 2003, 781). 
dad privada como algo que tiene que ser respetado (de ser así sería "sagrada"), sino también la noción de derecho como ficción que esconde las reales relaciones de fuerza vigente en la sociedad: "el derecho no volverá a la nada más que cuando haya sido absorbido por la fuerza, es decir, cuando se haya confirmado que "la fuerza es anterior al derecho" (Gewalt geht vor Recht) (Stirner, 1976, 212)". Mientras el revolucionario, como hemos visto, eleva el derecho por encima de si, el insurrecto no reconoce ni tampoco reivindica ningún derecho, sino que ensalza el uso de la fuerza individual. Como es evidente, Stirner anima el individuo a tomar un papel activo y propositivo en su liberación. Esta ya no depende de una fuerza externa (por ejemplo la sociedad comunista), ni del derecho, sino de la capacidad del individuo de ejercer cuanto más poder pueda:

La plebe no dejará de ser plebe hasta el día en que se apodere de lo que necesita y es plebe porque, por temor al castigo, no se atreve a tomarlo [...] La plebe solo puede ser ayudada por el egoísmo: esta ayuda debe prestársela a sí misma, y eso es lo que hará. La plebe es un poder, siempre que no se deje domar por el miedo (Íbid., 263).

Pues bien. Por lo dicho, queda claro que la noción stirneriana de propiedad abarca una dimensión más amplia, "existencial” y llega a constituir el verdadero núcleo de la Insurrección. Me refiero a lo que Stirner llama "propiedad de sî" (Eigenheit) y que opone explícitamente a la libertad:

¡Qué diferencia entre la libertad y la propiedad! (Eigenheit) [.... ¡La libertad no existe más que en el reino de los sueños! La individualidad, es decir, mi propiedad, es en cambio, toda mi existencia y mi esencia, es Yo mismo. Yo soy libre de lo que carezco, soy propietario de lo que está en mi poder o de aquello que puedo. [...] Yo no puedo querer verdaderamente la Libertad, pues no puedo realizarla, crearla; todo lo que puedo hacer es desearla y soñar con ella, pero sigue siendo un ideal, un fantasma. Las cadenas de la realidad infligen a cada instante a mi carne las más crueles heridas, pero yo sigo siendo Mi bien propio (Íbid., 161).

Así como la propiedad material no puede consistir solo en el objeto, sino más bien en la capacidad del sujeto de ejercer su fuerza sobre ello, de la misma manera una "verdadera" libertad no puede ser un objeto o una cosa (como quieren los liberales y los revolucionarios), sino que tiene que coincidir con la potencia del individuo. Además, mientras la libertad permanezca como una meta ideal, universal y abstracta, y no sea propiedad del individuo, este no logrará una real emancipación en tanto que será una libertad mutilada, o sea concedida al individuo por gracia de un amo. Pero, dice Stirner, el hombre al que se le da libertad "no es más que un esclavo liberado (Freigelassener), un libertinus, un perro que arrastra un extremo de la cadena" (Íbid., 171). Un ejemplo de esta libertad se encuentra en la famosa "cuestión judía", relativa a la libertad de culto de las minorías religiosas. Aunque, nota Stirner, se concediese más libertad al mahometano, al judío o al cristiano, por ejemplo como libertad de decir lo que le pase por la mente, él hablará exactamente como antes. No por tener más libertad, el mahometano, el cristiano o el judío serán más emancipados, en tanto permanezcan encadenados a su identidad religiosa. Si entonces la libertad de la 
cual gozamos en las sociedades liberales se parece a arenas movedizas, donde cuanto más ejerzamos la libertad, más nos vemos atrapados en formas rígidas de subjetividad (y en el régimen normativo que la concede), en cambio la Eigenheit es un agarre para salir de ellas. De hecho, distintamente de la libertad, la propiedad de sí es un proyecto abierto de ejercicio de la libertad, que reclama un papel activo del individuo:

Se ignora que toda libertad es, en la plena acepción de la palabra, esencialmente una auto-liberación (Selbst-befreiung), es decir, que Yo tan solo puedo tener tanta libertad como la cree Mi individualidad (Íbid., 170).

La "propiedad de sî" es pues un tipo de libertad radical que ya no consiste en realizar el ideal trascendental de la libertad sino en adquirir cada vez más autonomía o, si queremos, la "libertad para definir un camino propio hacia la libertad" (Newman, 2011, 200). Stirner, en otros términos, abandona el concepto de libertad como ser, para afirmar la libertad como poder. Mientras la primera es una "trascendencia" una aspiración que ha de ser realizada, la segunda es la libertad concreta porque corresponde al ejercicio del poder por parte del individuo. Si la libertad abstracta desposee al individuo de su fuerza, en cambio el ejercicio del poder "empodera" al individuo. Foucault mismo, a aquellos que le acusaban de tener una visión del poder omnipervasora y que no dejara espacio para el ejercicio de la libertad, replicaba "stirnerianamente" que el ejercicio de la libertad se anida precisamente en las relaciones de poder ya que "no existen relaciones de poder sin resistencias", siendo éstas tanto más eficaces precisamente cuando se forman allí donde se ejercen relaciones de poder. Por ello, "la resistencia al poder no tiene que venir de fuera para ser real, pero tampoco está atrapada por ser la compatriota del poder" (Foucault, 1979, 171). Esta manera de entender la libertad como ejercicio del poder y no como su negación (como quiere la mayor parte de la teoría anarquista contemporánea a Stirner) replantea, en la praxis, las reales posibilidades de resistencia. Si se renuncia de una vez por todas a aspirar al ideal de la libertad, se entiende que el individuo siempre ha sido libre en tanto siempre ha podido ejercer su potencia y, si no lo ha hecho, ha sido por renuncia voluntaria. Es decir, si la libertad no es una condición de ausencia de poder, sino más bien la capacidad del individuo de ejercer su poder, entonces el individuo puede ejercer resistencia incluso en las situaciones más desfavorables, incluso bajo tortura. Un hombre encadenado al cual se le imparten latigazos (el ejemplo es del mismo Stirner) tiene chance de liberarse de esta violencia y cambiar la situación en su favor solo si tiene la mira en él y en su interés, esto es, si es capaz de ser "propietario de sí mismo". Cualquier oposición ulterior es posible solo a partir de este acto de resistencia íntimo ${ }^{4}$.

Ahora bien. Hay otra, importante, diferencia entre la libertad y la Eigenheit que entraña la constitución ontológica del sujeto mismo. La libertad, como hemos visto, va siempre vinculada a la construcción de una determinada subjetividad gobernable. El mismo paradigma revolucionario se basa, después de todo, en la idea de que hay una esencia reprimida que tiene que ser liberada. Contrariamente a ello, la "propiedad de sî" stirneriana carece de

4 Se tiene la impresión que, a raíz de la lectura de Stirner, también Marx y Engels hayan incluido el cambio de la persona misma, la conversión del sujeto, como meta de la actividad revolucionaria: "en la actividad revolucionaria, el cambiarse coincide con el hacer cambiar las circunstancias" (Marx y Engels, 1974, 245). 
contenido (Freiheit ist inhaltsleer), en cuanto es una prerrogativa del individuo definirla cada vez. Si, juntos con Stirner, nos inclinamos a pensar el sujeto como sujeto vacío, que carece de toda esencia y que no tiene ningún telos que cumplir, la noción misma de libertad pierde de sentido:

un hombre no es "llamado" a nada; no tiene más "deber" y "vocación" que lo tienen una planta o un animal (Stirner, 1976, 332).

Stirner deja clara su aversión a cualquier idea de que "algo" tenga que ser realizado, una vocación (Beruf) o un deber:

¿Ustedes se buscan? Eso es porque aún no se poseen. ¿Ustedes se preguntan por lo que deben ser? ¡Entonces no lo son! Sus vidas no son más que largas y apasionadas esperas: durante siglos se ha vivido en la esperanza. Pero vivir es algo bien distinto en el disfrute de sí (Íbid., 237).

Según Stirner, "los más racionalistas e ilustrados" (es decir, los liberales), son aún más propensos al sacrificio que los cristianos ya que, mientras estos últimos solo sacrificaban su vida terrena al servicio de la vida celestial, los primeros se esfuerzan por cumplir "aquí y ahora" con el ideal de una vida exquisitamente humana. El orden liberal pos-revolucionario, como hemos visto, se basa en un dualismo o desdoblamiento (Entzweiung) del individuo que se ve llamado a realizar la esencia del buen ciudadano, del honrado trabajador, del verdadero hombre, etc. Esta ilusión de tener una identidad determinada, y el esfuerzo por vivir conforme con ella, tiene la ventaja de proporcionar al individuo cierta estabilidad, ante todo psicológica. Refugiándose en las convicciones (morales, políticas, etc.) de su tiempo, así como en los rituales de la vida diaria, el individuo se pierde en un anonimato reconfortante (algo parecido al heideggeriano Das-Man). Es el viejo deseo de querer dotar la existencia de un dato objetivo, de una esencia. Pero, según Stirner, en la medida en que el individuo sigue abocado a un ideal que realizar se convierte en el plautiano heautontimorumenos, en verdugo de sí mismo, que vive infeliz y culpable por no lograr estar a la altura de su esencia. Ser alienados (o "poseídos", en el lenguaje de Stirner) significa vivir la condición presente como imperfecta y creer que uno deba superarla convirtiéndose en alguien otro, en alguien "mejor". Toda idea de realización es, por ende, cómplice de un sistema de poder que acaba sacrificando la unicidad del individuo en tanto lo fractura entre lo que es (su existencia) y lo que debería ser (su esencia). Hay pues, según Stirner, dos posturas incompatibles ante la vida: la postura religiosa (cristiana y liberal), que toma la vida por una meta, una misión y una vocación que realizar; y la postura egoísta, que no busca realizar ninguna vocación, sino que trata la vida como su propiedad y, por ello, como objeto de aniquilación: "Ya no tiemblo por mi vida, sino que la "derrocho" (Íbid., 327). La Eigenheit stirneriana, en otras palabras, es un rechazo de todas las identidades que les son "ofrecidas" al individuo y una apuesta a la auto-determinación. La única manera para escapar del poder de subjetivación es, por lo tanto, abandonar la noción de "sujeto" como un conjunto estable y fijo de predicados y afirmar su radical indeterminación. Por esto Stirner llama también al Único "nada creadora" (schöpferische Nichts): 
Yo no me supongo, porque a cada instante me pongo o me creo; no soy sino porque soy puesto y no supuesto, y una vez más, no soy puesto sino en el momento en que me pongo; es decir, que soy a la vez el creador y la creación (Íbid., 156).

Distintamente del sujeto epistémico de la modernidad, el Único es un sujeto vacío, sin contenidos y sin un telos que realizar. No se trata de liberar la esencia humana de las trabas externas, sino precisamente liberar el yo de la esencia humana y de cualquier idea de realización. No se trata de convertirse en lo que uno es, sino en lo que uno no es o, esto es, "mantenerse abierto a la nada" (Penzo, 1981, 120). Él nunca coincide con sus atributos particulares, ninguna determinación puede representarlo por completo (a esto se refiere Stirner cuando dice que ha escrito un libro entero sobre una palabra vacía). En esta óptica, el "descontento del hombre consigo mismo" que Stirner pone en la base del acto de insurrección, ha de ser interpretado como un rechazo del sujeto contra si mismo, esto es contra la identidad como construcción ideológica:

El liberalismo, cualquiera que sea su matiz, tiene un enemigo mortal que le es tan irreductiblemente opuesto, como el diablo lo es a Dios: siempre al lado del hombre se levanta el no-hombre (Un-mensh), y el egoísta al lado del individuo. Estado, sociedad, humanidad, nada consigue desalojar a ese diablo de sus posiciones (Stirner, 1979, 144).

Stirner describe el no-hombre como un concepto límite, o mejor, como el límite con el cual se topa toda ideología o sistema de dominación. El orden simbólico no logra construir el individuo cómo sujeto o mejor, no lo logra del todo. El sujeto así constituido, nunca se siente en casa en las varias identidades que encarna a lo largo de su vida (de mujer, trabajador, etc.), que están constantemente desestabilizadas por la nada que demora en él. El sujeto, por lo tanto, nunca puede "formar una identidad completa porque esta falta nunca puede ser llenada" (Newman, 2005, 80-81).

Es posible comparar, aunque sea de paso, la propiedad de sí stirneriana al foucaultiano "cuidado de sí", a través del cual se procura "fomentar nuevas formas de subjetividad mediante el rechazo del tipo de individualidad que se nos ha impuesto durante varios siglos" (Foucault, 1988, 11). Efectivamente, igual que la Eigenheit, las "técnicas del cuerpo" difundidas en la antigüedad grecorromana y en las primeras comunidades cristianas, tenían por finalidad aumentar la capacidad del individuo de aumentar el poder de uno sobre uno mismo. Para Foucault, ser libre significa "no ser esclavo de sí mismo ni de los propios apetitos, lo que implica que uno establece en relación consigo mismo una cierta relación de dominio, de señorío, que se llamaba arché, poder, mando" (Foucault, 1994, 116). Mientras los aparatos confesionales del cristianismo y de la modernidad procuran descubrir una "verdad fundamental" escondida en el sujeto y, con ello, lo fabrican en tanto sujeto gobernable, para Stirner y Foucault, la libertad consiste en liberarse de aquellas formas de la subjetividad que nos mantienen encadenados a un sistema de poder:

Egoísmo, en el sentido cristiano de la palabra, significa algo así como interés exclusivo por lo que es útil al hombre carnal. Pero ¿esta cualidad de hombre carnal es, acaso, mi única propiedad? [...] ¿Obedezco a Mí mismo, a Mi propia decisión, 
cuando obedezco a la carne, a Mis sentidos? Yo no soy verdaderamente Mío (Mein eigen bin ich) sino cuando estoy sometido a Mi propio poder (mein Eigennutz) y no al de los sentidos o, por otra parte, al de cualquiera que no sea Yo (Dios, los hombres, la autoridad, la ley, el Estado, la Iglesia, etc.) (Stirner, 1979, 172).

El egoísmo stirneriano es pues una estrategia ética de auto-posesión o autodominación que nada tiene a que ver con la voluntad de acumulación de beneficios o con el cálculo interesado del provecho. El propio Stirner, de hecho, se apresura a distinguir su egoísmo del "egoísmo vulgar" del pequeño burgués, "esclavo del sucio lucro" (sic) que se somete a toda clase de privaciones y esfuerzos para alcanzar una meta particular e inauténtica, pero también toma distancia del egoísmo del libertino, el kierkegaardiano Don Juan que se sacrifica a la búsqueda frenética del placer y se queda esclavo de ello ya que, a fin de cuentas, "el Mammón terrestre y el Dios del cielo exigen exactamente la misma suma de renuncia" (Íbid., 66). El egoísmo ético, en pocas palabras, consiste en aquella capacidad de auto-gobierno que brinda la "propiedad de sî" y que libera el individuo no solo de la voluntad de otro, sino también de sus mismos apetitos serviles. La subjetividad que emerge a través de esta práctica, es la de un individuo con un agudo sentido de la autonomía y con una conciencia incontaminada y reactiva, que abandona orgullosamente las tendencias uniformadoras de su época y fortalece lo que, con Schopenhauer, podríamos llamar el "sentido oceánico de la individualidad"s.

\section{Conclusión. La "inactividad revolucionaria"}

En este artículo hemos analizado la noción stirneriana de insurrección, comparándola con la de revolución. Se ha visto que el alcance de la insurrección es mucho mayor que el de la revolución, porque no se limita a derrumbar las trabas externas que acotan la libertad del individuo, sino ante todo a poner en entredicho el apego apasionado a las formas de subjetividad que nos oprimen. Esto no significa que revolución e insurrección sean incompatibles, sino que si la revolución no va precedida del sutil trabajo de la insurrección, está destinada a repetir todo el sistema de dominación arqueo-teológico. Del mismo modo, Stirner sería un crítico también de las identity politics tal y como lo fue, en su días, de las peticiones de reconocimiento de las minorías religiosas. Ellas serían, a los ojos de Stirner, no solo un ejemplo de pérdida de la unicidad del individuo, que renuncia a su Eigenheit para perderse en alguna identidad colectiva, un enésimo "espectro", sino sobre todo una nueva, y más sutil, técnica de disciplinamiento del individuo. Además, las identity poli-

5 No sorprende que la figura del Único atrajese también a teóricos de derechas. No solo, como es sabido, Schmitt y Jünger, sino también el "teórico de la raza" italiano Julius Evola que admite en su biografía que "Stirner fue una de mis primeras lecturas", cuando buscaba "la afirmación de principios de una moral aristocrática y de los valores de un ser que se desvincula de toda relación y que se da a sí mismo su propia ley". Así, en su Teoria dell'individuo assoluto, Evola usa indiferentemente la palabra Único en lugar de la de individuo absoluto. Lo que fascinaba al italiano era sobre todo la figura del Einzige como potencia irrefrenable e ilimitada, más allá de toda norma, moral o convención social (Evola, 1973). Evola asimila el Einzige stirneriano a la figura del autarca, esto es un hombre nuevo y arcaico a la vez, que sea el protagonista de la actual disolución de la civilización, que "tiene que convertirse a si mismo en extrema razón. El stirneriano ich habe meine sache auf nichts gestellt tiene que ser para él una realidad viviente" (Evola, 1981,98). 
tics, ceñidas sobre la idea de una identidad oprimida, tienen un efecto de-politizador, en tanto razonan en términos de luchas de identidades. Pero, como mostró Stirner, construirse alrededor de una identidad es precisamente convertirse en un sujeto gobernable. Haciendo de eco a Stirner, Wendy Brown, teórica de la política feminista, nota cómo algunas luchas de género están a menudo construidas alrededor de una identidad vulnerable (la victima), ofendida por el otro. De allí el problemático deseo de protección por parte del mismo orden liberal. Como Stirner vio claramente, también según Brown, en la medida en que las identidades "oprimidas" formulan sus demandas de reconocimiento en términos de derechos y libertades, acaban voluntaria o involuntariamente vinculándose todavía más al Estado, del cual depende su reconocimiento (Brown, 1995, 21).

Otra, como hemos visto en este escrito, es la vía de la insurrección. Contra todo esencialismo, Stirner logra pensar una subjetividad "ingobernable" cuyo fundamento está en el abismo (el heideggeriano Ab-grund ist ab-Grund), sin esencia ni telos que realizar. La insurrección pues no busca otra forma de gobernabilidad sino una manera para convertir el individuo en ingobernable. Solo liberando la experiencia de la tiranía de los principios y de las finalidades supremas, se abre el espacio para la acción indeterminada y libre, esto es, finalmente liberada de la dictadura del telos, del reino de los fines y de la racionalidad estratégica. El Einzige mismo es el "sitio negativo", el rechazo de toda identidad positiva o vocación, es la negativa a dejarse definir por alguna propiedad o esencia. Pero esta negatividad radical, como hemos visto, no desemboca en pasividad, sino que entraña una política de emancipación que consiste en una apuesta por la autonomía. A su pesar pues, tenía razón Marx cuando afirmaba, despectivamente, que:

La revolución y la sublevación stirneriana no se distinguen, como cree Stirner, por el hecho de que la una sea un acto político o social y la otra un acto egoísta, sino por el hecho de que la una es un acto y la otra no lo es (Marx y Engels, 1974, 448).

A pesar de que, con ello, Marx quisiese acusar a Stirner de idealismo, tachando la Empörung de ser una revuelta toda interna a la conciencia y que deja la realidad tal y como es, se puede tomar la acusación de Marx a la letra. La Empörung no es, literalmente, un acto sino una in-actividad, una sustracción ontológica al existente. Ella no solo toma las distancias del modelo revolucionario, como hemos visto ampliamente, pero también de aquellas prácticas de "ensimismamiento" new-age en boga hoy en día ("budismo occidental", habría dicho Nietzsche), que solo suponen un paliativo a la insatisfacción del presente. La insurrección stirneriana puede ser vista como una "retracción", una política del éxodo, que nada tiene a que ver con una desesperanzada aceptación del existente o una renuncia a la transformación, sino más bien una sustracción del consenso individual (Bargu, 2011, 114-116). Se trata de algo como una inactividad revolucionaria, un rechazo, ante todo ontológico, a encarnar un rol, un papel socialmente aceptado y entonces a "funcionar automáticamente" como parte de la Máquina. También hoy en día, cierto hiper-activismo relacionado con muchas nobles causas sociales (del reciclaje de alimentos a peticiones para la igualdad de género) sigue siendo una participación, y no una sustracción, al orden vigente. Además una participación, nos diría Stirner, que brinda a quien la ejerce una cierta identidad en la cual ampararse (ecologista, feminista, etc.). En cambio, la noción de praxis 
en Stirner está libre de la dictadura de la acción y de la realización de una finalidad última. Es más, ya antes de dar a la imprenta el Der Einzige, en un escrito considerado "menor", El Falso principio de nuestra educación (1842), Stirner brindaba una definición de praxis que no se podía reducir al mero pragmatismo, y que en cambio tuviera que abarcar valores de oposición basados en un sincero sentido de la individualidad:

...la verdadera praxis no es la de buscarse la vida: el saber vale demasiado como para que sea lícito gastarlo en perseguir los fines prácticos de uno. La praxis más alta consiste, por el contrario, en que un hombre libre se revele a sí mismo; y el saber que sabe morir es la libertad que nos da vida (Stirner, 2013, 48).

Contra el "mero pragmatismo" que acaba re-produciendo las fuerzas de opresión existentes, Stirner aboga por la "capacidad de oponerse" al existente, que algunos autores han comparado con el Gran Rechazo marcusiano (Fleishmann, 1971, 220-229). Ernst Jünger, admirador de Stirner, capta el carácter radical de la insurrección stirneriana y su distancia respecto de demás proyectos políticos tradicionales, incluso el anarquismo. El anarquista es un hombre que tiene planes (como el matar al zar, por ejemplo) mientras el anarca jungeriano (figura mutuada del Einzige) "no constituye una excepción, no representa una élite; se oculta más bien en cada uno". De hecho, según Jünger hay una condición que caracteriza al hombre contemporáneo y que hace de él un potencial anarca y es la de haberse convertido en apátrida y aislado, "viéndose finalmente expuesto al aniquilamiento" (Jünger, 1963, 40). Todos los hombres están expuestos hoy en día a estas condiciones pero solo aquel que, en la masa, elije tener un destino propio más bien que ser considerado un número, es un rebelde. Este, de hecho, está dispuesto a hacer "un acto de libertad en la catástrofe" y pasar al bosque, esto es, encontrar un sitio de resistencia, una patria de los que no tienen patria, que se puede encontrar por doquier y "hasta puede hallarse en el suburbio de una gran ciudad" (Íbid., 74). La insurrección, así como la emboscadura jungeriana, puede ser practicada por doquier y sobretodo en cualquier momento, siendo en esto lo más parecido a la revolución de la vida diaria de la cual hablaban los situacionistas (Vaneigem, 1977). La insurrección, en conclusión, es expresión de este rechazo radical y de un tipo de resistencia que no consiste en la febril búsqueda de alternativas, sino más bien en una retracción, una defección del existente, a través de la cual el individuo se niega a prestar su consenso. Recuperar esta negatividad es, en conclusión, la tarea de toda verdadera insurrección. Y se trata de una difícil tarea hoy en día ya que, como ha notado Schürmann, "no existe fórmula más segura para asegurar el isomorfismo social que apelar a la particularidad de cada uno" (Schürmann, 1986, 305). Al reclamar la personalidad única de cada cual, sus sentimientos, sus gustos, su estilo de vida y sus creencias, cada uno hace exactamente lo que hacen todos los demás y, por ello "promueve la uniformidad en el mismísimo acto de negarla". Resistiéndose a un poder que es cada vez más positivo y propositivo, el Único afirma su individualidad disconforme y negadora del "optimismo criminal", para decirlo en las palabras de Albert Caraco. En una época en que es vital ser alguien, el Único prefiere, impopularmente, seguir siendo un Don Nadie. "Nadie" es, después de todo, quien mata al ciclope Polifemo. 


\section{Agradecimientos}

Quiero expresar mi gratitud a los/as dos revisores/as anónimos/as que, con sus concienzudos comentarios, han contribuido a mejorar sustancialmente este trabajo.

\section{Bibliografía}

Agamben, Giorgio (1996), La comunidad que viene, Pre-Textos, Valencia.

Agamben, Giorgio (2005), Profanaciones, Adriana Hidalgo, Buenos Aires.

Arendt, Hannah (1992), Sobre la revolución, Siglo XXI Editores, Buenos Aires.

Balibar, Etienne (1995), “Ambiguous Universality”, Differences: a journal of feminist cultural studies 7 (1): 48-72.

Bargu, Banu (2011), "Max Stirner, Postanarchy avant la lettre', en Jimmy Casas Klausen and James Martel (eds.), How Not to be Governed: Readings and Interpretations from a Critical Anarchist Left, Lexington Books, Lanham MD, 103-122.

Brown, Wendy (1995), States of Injury: Power and Freedom in Late Modernity, Princeton University Press, Princeton.

Camus, Albert (1978), El hombre rebelde, Losada, Buenos Aires,

Castoriadis, Cornelius (1990): "Does the Idea of Revolution Still Make Sense?" Thesis Eleven (26): 123-38.

Evola, Julius (1973), Teoria dell'individuo assoluto, Roma, Mediterranee, Roma.

Evola, Julius (1981), Saggi sull'idealismo mágico, lkaest, Roma

Fleischmann, Eugene (1971), 'The Role of the Individual in Prerevolutionary Society', en Pelczynski, Zbigniew (eds.), Hegel's Political Philosophy, Cambridge University Press, Cambridge.

Foucault, Michel (1979), Microfisica del poder, Ediciones de la Piqueta, Madrid.

Foucault, Michel (1988), "El Sujeto y el Poder", Revista Mexicana de Sociología, (50)3: 3-20.

Foucault, Michel (1994), Herméneutica del sujeto, La Piqueta, Madrid.

Foucault, Michel (2007), El nacimiento de la biopolítica. Curso en el College de France (1978-1979), FCE, Buenos Aires.

Jünger, Ernst (1963), Tratado del rebelde, Ed. Sur, Buenos Aires.

Kelsen, Hans (2009), Teoría pura del derecho, Eudeba, Buenos Aires.

Koselleck, Reinardt (2012), Historia de conceptos. Historia sobre semántica y pragmática del lenguaje político y social, Trotta, Madrid.

Leopold, David (2003), “A Left-hegelian Anarchism”, The European Legacy, (8) 6: 777-786. Lyotard, Jean-François (1987), La condición posmoderna, Gedisa, Barcelona.

Marx, Karl; Engels, Friedrich (1974), La Ideología Alemana, Ediciones Grijalbo, Barcelona.

Marx, Karl (2006), Paginas Malditas. Sobre la cuestión judía y otros textos, Libros de Anarres, Buenos Aires.

Newman, Saul (2005), Power and Politics in Post-structuralist Thought, Routledge, New York.

Newman, Saul (2011), Max Stirner, Palgrave Macmillian, Londres.

Penzo, Giorgio (1981), Max Stirner. La rivolta esistenziale, Patron, Bologna. 
Pessoa, Fernando (1990), en Teresa Rita Lopes (eds.), Pessoa por conhecer, Volumen 1, Editorial Estampa, Lisboa.

Proudhon, Pirre-Joseph (1937), Las confesiones de un revolucionario. Para servir a la historia de la revolución de febrero de 1848, Americalee, Buenos Aires.

Schürmann, Reiner (1986), Heidegger on Being and Acting. From Principles to Anarchy, Indiana University Press, Bloomington.

Sini, Carlo (1984), "Stirner, Nietzsche e l'ambiguità dellindividuo moderno", en Pietro Ciaravolo (eds.), Nietzsche-Stirner, Editoriale B.M. Italiana, Roma.

Stirner, Max (1976), El Único y su propiedad, Pablos Editor, S.A., México.

Stirner, Max (2013), Escritos Menores, Pepitas de Calabaza, La Rioja.

Vaneigem, Raul (1977), Tratado de saber vivir para uso de las jóvenes generaciones, Anagrama, Barcelona.

Wagner, Peter (2001), Theorizing Modernity: Inescapability and Attainability in Social Theory, Sage, Londres.

Zizek, Slavoj (2001), El espinoso sujeto. El centro ausente de la ontología política, Paidos, Buenos Aires. 